\title{
Performed Eligibility Criterion Not Applicable Indicator
}

National Cancer Institute

\section{Source}

National Cancer Institute. Performed Eligibility Criterion Not Applicable Indicator. NCI

Thesaurus. Code C93916.

Specifies whether the specific eligibility criterion is not applicable to this participant. 